\title{
Leishmaniose Visceral em Doentes com Infeção VIH: O Desafio da Recaída e Falência Terapêutica
}

\author{
Visceral Leishmaniasis in HIV-Infected Patients: The \\ Challenge of Relapse and Treatment Failure
}

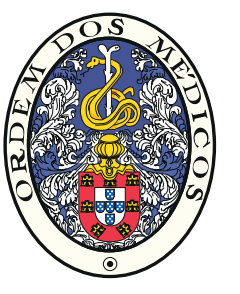
Patrícia CIPRIANO $\triangle 1$ 1, Ana Cláudia MIRANDA², Isabel ANTUNES², Kamal MANSINHO²
Acta Med Port 2017 Jun;30(6):443-448 - https://doi.org/10.20344/amp.8291

\section{RESUMO}

Introdução: A leishmaniose visceral é uma infeção disseminada endémica, considerada a terceira infeção parasitária oportunista mais frequente na Europa. É mais prevalente nos doentes co-infetados por vírus da imunodeficiência humana, em que acarreta um grande desafio terapêutico pelo risco acrescido de recaída. O objetivo do estudo é a caraterização de uma população co-infetada e da eficácia dos esquemas terapêuticos.

Material e Métodos: Estudo retrospetivo de uma amostra seleccionada de todos os doentes com leishmaniose visceral e infeção pelo vírus da imunodeficiência humana internados num período de 10 anos num serviço de Infeciologia.

Resultados: Foram incluídos 23 doentes co-infetados, dois do sexo feminino $(8,7 \%)$. A contagem média de células $\operatorname{TCD}_{4+}$ à data do diagnóstico da leishmaniose visceral foi de 104,4 cels/uL ( $\pm 120,3$ cels/uL), apenas dois doentes tinham carga viral indetetável (<20 cópias $/ \mathrm{mL})$ e 16 (69,6\%) não cumpriam terapêutica antirretroviral à data do diagnóstico. Como terapêutica optou-se por anfotericina B lipossómica em 18 doentes, antimoniato de meglumina em quatro e miltefosine num caso. Catorze $(60,9 \%)$ aderiram a esquema de profilaxia secundária. Verificou-se uma taxa de recaída de $26,1 \%$ (seis doentes).

Discussão: A co-infeção leishmaniose-vírus da imunodeficiência humana está associada a maior taxa de falência terapêutica e recaída, sendo a contagem de células $T C D_{4+}$ o principal fator preditivo de recaída e o cumprimento de esquemas de quimioprofilaxia inequívoco na redução da mesma. A terapêutica combinada com anfotericina B lipossómica e miltefosine regista taxas de falência inferiores ao esquema clássico.

Conclusão: Conclui-se que esquemas alternativos e combinados parecem ser uma alternativa nesta população.

Palavras-chave: Falência Terapêutica; Leishmaniose Visceral; Recidiva; Infecções por VIH

\section{ABSTRACT}

Introduction: Visceral leishmaniasis is an endemic disseminated infection, considered to be the third most frequent opportunistic parasitic infection in Europe. It is especially prevalent in patients co-infected with human immunodeficiency virus, in whom it poses a great therapeutic challenge due to increased risk of relapse. The goal of this study is to characterize a population of co-infected patients, as well as the efficiency of the adopted treatment strategies.

Material and Methods: Retrospective study with a sample composed of all patients with visceral leishmaniasis and human immunodeficiency virus admitted in an Infectious Diseases ward over a period of 10 years.

Results: Of the 23 enrolled patients, two were female (8.7\%). The mean $\mathrm{TCD}_{4+}$ cell count was 104.4 cells/uL ( $\left.\pm 120.3 \mathrm{cells} / \mathrm{uL}\right)$, only two patients had undetectable viral load $(<20$ copies $/ \mathrm{mL})$ and $16(69.6 \%)$ were not under antiretroviral therapy at the time of diagnosis. Treatment-wise, liposomal amphotericin B was used in 18 patients, meglumine antimoniate in four and miltefosine in one. Fourteen $(60.9 \%)$ were adherent to secondary prophylaxis protocol. A relapse rate of $26.1 \%$ was observed (six patients).

Discussion: Co-infection is responsible for higher treatment failure rates and more relapses. $\mathrm{TCD}_{4+}$ cell count is the main predictive factor of relapse, and strict adherence to chemoprophylaxis protocols unequivocally results in a reduction of relapse rate. Combined treatment strategies using liposomal amphotericin B and miltefosine yield fewer therapeutic failures than the classic approach.

Conclusion: We therefore conclude that alternative, combined therapeutic protocols seem to be a viable solution for these patients.

Keywords: HIV Infections; Leishmaniasis, Visceral; Recurrence; Treatment Failure

\section{INTRODUÇÃO}

A leishmaniose é uma infeção protozoária, transmitida através da picada de insectos flebotomíneos existindo mais de 20 espécies de Leishmania e mais de 90 espécies de flebotomíneos. ${ }^{1}$ A nível mundial, a leishmaniose pode apresentar-se de duas formas: a forma zoonótica (Leishmania infantum / Leishmania chagasi) tem o cão como principal reservatório e localiza-se essencialmente na zona da bacia mediterrânea, Médio Oriente, China e América do Sul e a forma antropomórfica (Leishmania donovani), cujo reservatório é o próprio homem, mais prevalente na Índia e costa oriental de África. ${ }^{2} \mathrm{~A}$ infeção por Leishmania em indivíduos imunocompetentes mantém-se habitualmente assintomáti- $\mathrm{ca}^{3}$ contudo, dependendo da situação imunitária do doente, pode apresentar-se como doença localizada ou disseminada, nomeadamente leishmaniose cutânea ou das mucosas ou ainda como leishmaniose visceral (LV), doença sistémica conhecida por kala-azar (palavra hindi para 'febre negra'), a forma mais grave da doença, potencialmente fatal se não for tratada. ${ }^{4}$

A LV é endémica em mais de 60 países, estando mais de 350 milhões de pessoas em risco. ${ }^{2}$ De acordo com dados da Organização Mundial de Saúde (OMS), no ano 2013 mais de dois milhões de doentes foram afectados, registando-se 20 a 30 mil mortes causadas pela infeção,

\footnotetext{
1. Serviço de Medicina Interna. Hospital de Cascais. Cascais. Portugal.

2. Serviço de Infeciologia. Hospital de Egas Moniz. Centro Hospitalar Lisboa Ocidental. Lisboa. Portugal.

$\triangle$ Autor correspondente: Patrícia Cipriano. patriciacocipriano@gmail.com

Recebido: 10 de outubro de 2016 - Aceite: 16 de fevereiro de 2017 | Copyright $\odot$ Ordem dos Médicos 2017
} 
sendo estimados 200 a 400 mil novos casos de LV a cada ano em todo o mundo. Apesar de ser uma doença amplamente dispersa, mais de $90 \%$ dos casos descritos encontram-se concentrados em seis países - Índia, Bangladesh, Sudão, Sudão do Sul, Etiópia e Brasil, ${ }^{5,6}$ A região mediterrânica representa 5\% - 7\% do peso global da leishmaniose, com uma incidência anual de 1200 a 2000 novos casos, ${ }^{7}$ sendo considerada a terceira infeção parasitária oportunista mais frequente na Europa. ${ }^{8} \mathrm{Em}$ Portugal, foram descritos pelo Instituto de Higiene e Medicina Tropical, entre 2000 e 2009, 173 casos de LV, 66 destes diagnosticados em imunocompetentes e 107 em co-infetados pelo vírus da imunodeficiência humana $(\mathrm{VIH}){ }^{1}$

A LV tem um período de incubação de dois a seis meses, podendo ser muito menor em doentes gravemente imunocomprometidos. ${ }^{9} \mathrm{~A}$ relação entre doença sintomática e infeção assintomática ou subclínica é superior a 1:30, e a maior parte destes últimos têm parasitas viáveis toda a vida, podendo surgir uma reativação em caso de imunossupressão. ${ }^{6}$ A apresentação clínica clássica inclui febre, hepatomegália, esplenomegália e pancitopenia, por vezes acompanhada de síndrome constitucional com astenia, perda ponderal, adenopatias ou envolvimento mucocutâneo, do sistema digestivo, respiratório ou renal. A clínica é semelhante entre imunocomprometidos e imunocompetentes embora nos primeiros possa ser mais exuberante. A esplenomegalia, por sua vez, pode ser menos pronunciada nos doentes imunodeprimidos. ${ }^{10}$

Para o diagnóstico definitivo é obrigatória a identificação de formas amastigotas do parasita em esfregaço ou exame cultural, seja de sangue periférico, aspirado medular ou biopsia de órgão. A coloração Giemsa tem uma sensibilidade de aproximadamente $70 \%$ no aspirado medular, enquanto a cultura em meio Novy-McNeal-Nicolle (até quatro semanas) tem uma sensibilidade entre $60 \%-85 \%{ }^{4}$ Estão ainda disponíveis serologias séricas [indirect flurescent antibodies (IFA), enzyme-linked immunosorbent assays (ELISAs), direct agglutination test (DAT), recombinant kinesin antigent (rK39)] e antigénio urinário (Kala-azar latex agglutination test - Katex]. As serologias permanecem positivas após terapêutica eficaz pelo que não devem ser consideradas isoladamente para o diagnóstico. Ao contrário das serologias, o antigénio urinário negativiza rapidamente após sucesso terapêutico, pelo que tem uma maior sensibilidade. No entanto, a técnica molecular de Polimerase Chain Reaction (PCR) tem maior sensibilidade no sangue medular que o esfregaço ou exame cultural, ${ }^{11}$ sendo que na população co-infetada por VIH apresenta uma sensibilidade de $92 \%$ e uma especificidade de $96 \%{ }^{7}$

Do ponto de vista terapêutico existem vários fármacos aprovados no tratamento da LV. O grupo dos antimoniatos (stibogluconato de sódio e antimoniato de meglumina), com importância histórica e efeitos tóxicos consideráveis, foi o primeiro a ser introduzido e a sua utilização levou ao desenvolvimento de resistências principalmente na região da Índia, actualmente com taxas de cura de apenas 50\%. O fármaco preconizado hoje em dia como gold standard é a anfotericina B em formulação lipossómica, pelo seu curso terapêutico vantajoso, menos efeitos secundários, habitualmente indicada no doente imunocompetente na dose de 3 $\mathrm{mg} / \mathrm{kg} / \mathrm{dia}$ durante cinco dias. ${ }^{12} \mathrm{Na}$ verdade, a OMS concluiu que, independentemente do esquema utilizado, uma dose cumulativa de $20 \mathrm{mg} / \mathrm{kg}$ é adequada para se atingir uma elevada taxa de cura na população imunocompetente em todas as regiões do mundo. ${ }^{13}$ Nos doentes com VIH, nomedamente na região mediterrânica, os esquemas terapêuticos incluem doses de anfotericina $B$ lipossómica de 20 - $60 \mathrm{mg} / \mathrm{kg}$ em vários esquemas possíveis (evidência BI-III). ${ }^{7}$ Posteriormente, surgiram fármacos de segunda linha, nomeadamente a paromomicina, pentamidina e miltefosine, a primeira terapêutica aprovada para a LV em formulação oral. ${ }^{12}$

No entanto, os doentes co-infetados por VIH tornam-se um desafio terapêutico, uma vez que para além de serem uma população com maior probabilidade de LV com apresentações atípicas, têm ainda maior risco de evolução para cronicidade, elevado risco de recaída e má resposta à terapêutica o que implica profilaxia secundária e follow-up apertado (clínico e biológico). ${ }^{8}$ Os autores propõem-se estudar uma população de co-infetados LV-VIH, salientando os casos de falência terapêutica, a prevalência das recaídas e a necessidade de novas abordagens terapêuticas nesta população. O objetivo é caracterizar os casos de LV em doentes co-infetados por VIH internados no serviço de Infecciologia de um hospital terciário num período de 10 anos e avaliar a eficácia versus falência dos esquemas terapêuticos utilizados.

\section{MATERIAL E MÉTODOS}

Estudo retrospetivo observacional, com amostra de conveniência selecionada de forma não probabilística e intencional, constituída por todos os doentes internados, com o diagnóstico de LV e co-infeção VIH, no período de janeiro de 2006 a dezembro de 2015 num serviço de Infeciologia.

Foram excluídos doentes cujos processos clínicos não foram disponibilizados e um doente com LV não co-infetado com VIH. Foram definidas como principais variáveis a idade, género, comorbilidades, estadiamento imunológico (avaliado pela contagem de células $\mathrm{TCD}_{4+}$ ), ARN VIH plasmático, instituição de terapêutica antirretroviral (TARV), com ou sem inibidores da protease (IP), sinais e sintomas, alterações laboratoriais, método de diagnóstico de LV, terapêutica de LV, profilaxia e primeira recaída.

A base de dados e análise estatística foram feitas com recurso ao programa Statistical Package for Social Science - SPSS ${ }^{\circledR}$ para Windows ${ }^{\circledR}$ versão 20.0.

\section{RESULTADOS}

No período de 10 anos foram diagnosticados 23 doentes com LV e co-infeção VIH. A média de idades dos doentes foi de 37,2 anos ( $\pm 6,3$ anos) com um mínimo de 27 anos e máximo de 48 anos. Apenas dois doentes eram do sexo feminino $(8,7 \%)$. Três tiveram o diagnóstico inaugural de infeção por VIH em simultâneo com o de LV. A maioria 
Tabela 1 - Caraterização demográfica e imunológica dos doentes co-infetados com LV-VIH no momento do diagnóstico de LV

\begin{tabular}{|c|c|c|c|c|c|c|c|c|}
\hline Caso & Género & Idade & TARV & $\begin{array}{l}\text { Carga viral } \\
\text { (cópias } / \mathrm{mL} \text { ) }\end{array}$ & $\begin{array}{l}\text { Células } \mathrm{TCD}_{4+} \\
\text { (céls/uL) }\end{array}$ & Terapêutica & $\begin{array}{l}\text { Profilaxia após } \\
1^{\circ} \text { episódio }\end{array}$ & $\begin{array}{l}\text { Meses entre fim da } \\
\text { terapêutica e recaída }\end{array}$ \\
\hline 1 & Masculino & 30 & Não & 287771 & 14 & $\begin{array}{l}\text { Anfotericina B } \\
\text { lipossómica }\end{array}$ & Pentamidina & 12 \\
\hline 2 & Masculino & 40 & Não & 414122 & 53 & $\begin{array}{l}\text { Anfotericina B } \\
\text { lipossómica }\end{array}$ & Não* & 19 \\
\hline 3 & Masculino & 39 & $\begin{array}{l}\text { Sim, } \\
\text { com IP }\end{array}$ & $<20$ & 281 & $\begin{array}{l}\text { Anfotericina B } \\
\text { lipossómica }\end{array}$ & $\begin{array}{l}\text { Anfotericina B } \\
\text { lipossómica }\end{array}$ & 16 \\
\hline 4 & Masculino & 35 & $\begin{array}{l}\text { Sim, } \\
\text { sem IP }\end{array}$ & $<20$ & 100 & $\begin{array}{l}\text { Anfotericina B } \\
\text { lipossómica }\end{array}$ & $\begin{array}{l}\text { Anfotericina B } \\
\text { lipossómica }\end{array}$ & 14 \\
\hline 5 & Masculino & 31 & Não & 28077 & 362 & $\begin{array}{l}\text { Anfotericina B } \\
\text { lipossómica }\end{array}$ & Pentamidina & $18^{* *}$ \\
\hline 6 & Masculino & 28 & Não & 1034958 & 28 & $\begin{array}{l}\text { Anfotericina B } \\
\text { lipossómica }\end{array}$ & Não* & 24 \\
\hline
\end{tabular}

TARV: Terapêutica anti-retroviral; IP: Inibidor da protease

* Dois doentes não fizeram esquema de profilaxia secundária por abandono da consulta, apesar de indicação formal;

** O óbito do doente número cinco na primeira recaída não foi directamente atríbuído à LV uma vez que apesar de ter mantido quimioprofilaxia não aderiu a TARV e evoluiu para um estado de grave comprometimento imunológico que associou à co-infeção LV-VIH uma tuberculose disseminada grave, à qual não resistiu.

(78,3\% N = 18) apresentava infeção por VIH estádio C3 dos CDC (Center for Disease Control Atlanta), prévia ao diagnóstico de $L V$, sendo a contagem média de células $T C D_{4+}$ à data do diagnóstico de LV de 104,4 cels/uL ( $\pm 120,3$ cels/ $u L)$.

Verificou-se ainda que a maioria não cumpria TARV $(69,6 \%, n=16)$ à data do diagnóstico de LV. Dos que estavam sob terapêutica apenas dois doentes se encontravam com ARN VIH plasmático indetetável (<20 cópias $/ \mathrm{mL}$ ) e apenas quatro doentes estariam a cumprir esquema incluindo IP.

No que diz respeito a comorbilidades identificadas, 20 doentes eram ex-utilizadores de drogas endovenosas, 18 apresentavam co-infeção por vírus da hepatite $\mathrm{C}$ e nove apresentavam infeção concomitante por Mycobacterium tuberculosis (pulmonar, ganglionar ou disseminada), destacando-se ainda cinco casos de pneumocistose. No que diz respeito à sintomatologia, salientou-se a febre $(73,9 \%$ dos casos), dor abdominal e enfartamento pós prandial (respectivamente $34,8 \%$ e $17,4 \%$ ), sudorese nocturna e diarreia (13\% cada). Ao exame objetivo destaca-se a esplenomegalia em $91,3 \%$ dos casos e hepatomegália em $87 \%$, sendo a perda ponderal o terceiro sinal mais frequente $(34,8 \%)$. Nos achados laboratoriais destacam-se a pancitopenia $(39,1 \%)$ ou bicitopénias (26\%), bem como a elevação das transaminases $(30,4 \%)$.

Perante a suspeita clínica de LV o diagnóstico definitivo foi realizado, na maior parte dos casos, por mais do que um método de diagnóstico: em três doentes foi positivo o exame direto do aspirado medular para formas amastigotas de Leishmania spp, em 10 casos o exame cultural (aspirado medular e/ou sangue periférico) e em nove casos foi positiva a PCR também no aspirado medular e/ou sangue periférico. Em sete casos foi ainda possível a identificação de formas de Leishmania spp em biopsias de outros tecidos, nomeadamente de biopsia gástrica/duodenal $(n=3)$, hepática $(n=2)$ ou ainda pleural ou da mucosa nasal $(n=1$ respetivamente).
Do ponto de vista terapêutico foi utilizada como primeira opção terapêutica a anfotericina B em formulação lipossómica em 18 doentes. A duração dos tratamentos com anfotericina $B$ lipossómica não foi uniforme na medida em que em alguns casos se optou por esquema de cinco dias com dose de $5 \mathrm{mg} / \mathrm{kg} / \mathrm{dia}$ e noutros o esquema foi com interrupções $(2,5-3 \mathrm{mg} / \mathrm{kg} / \mathrm{dia}$ durante cinco dias consecutivos e depois com mais cinco tomas respetivamente nos $7^{\circ}, 14^{\circ}$, $21^{\circ}, 28^{\circ}$ e $35^{\circ}$ dias, habitualmente já em ambulatório) sempre com o objetivo de uma dose total cumulativa mínima de $20 \mathrm{mg} / \mathrm{kg}$, habitualmente $40 \mathrm{mg} / \mathrm{kg}$. Destacam-se apenas como iatrogenia dois casos de lesão renal aguda. Quatro doentes realizaram antimoniato de meglumina $(20 \mathrm{mg} / \mathrm{kg}$ durante 21 dias), um deles complicado com pancreatite aguda iatrogénica e um realizou, como primeira linha, miltefosine $100 \mathrm{mg}$ dia durante 28 dias.

Catorze doentes $(60,9 \%)$ tiveram cura inicial documentada e iniciaram esquema de profilaxia ou terapêutica de manutenção tendo os restantes abandonado o seguimento após alta clínica. Os esquemas de quimioprofilaxia foram feitos em quatro doentes com pentamidina $6 \mathrm{mg} / \mathrm{kg}$ a cada três semanas e em 10 com anfotericina B lipossómica 4 $\mathrm{mg} / \mathrm{kg}$ de 21 em 21 dias. O objetivo seria manter quimioprofilaxia até se verificar uma contagem de células $T C D_{4+}$ consistentemente superior a 200 céls/uL durante um período mínimo de seis meses mas vários abandonaram o seguimento, não tendo sido possível quantificar o tempo de profilaxia cumprida.

Nenhum doente que manteve seguimento tem registo de falência terapêutica inicial. No entanto, de um total de 23 doentes tratados, definiram-se seis recaídas $(26,1 \%)$, ou seja, reaparecimento de formas de Leishmania spp em exame direto ou cultural após cura inicial documentada (Tabela 1). O valor pode ser subestimado uma vez que naqueles que abandonaram o seguimento, não tendo sido feita a pesquisa do parasita após terapêutica, não se consegue ter a certeza da eficácia da mesma. O tempo médio registado até à primeira recaída foi de 17,2 meses $( \pm 4,2)$ com 
mínimo de 12 e máximo de 24 meses. Salienta-se ainda que à data do diagnóstico, entre os seis doentes que recaíram, quatro não cumpriam TARV, não tinham carga viral suprimida e apresentavam contagem de células $\mathrm{TCD}_{4+}$ inferior a 100 céls/uL. Apenas um deles apresentava esquema de TARV com IP. No que diz respeito a profilaxia, apenas dois dos doentes que recaíram não cumpriram qualquer quimioprofilaxia por abandono terapêutico. Verificou-se um único óbito na primeira recaída, não directamente devido a LV, mas sim ao grave comprometimento imunológico do doente.

\section{DISCUSSÃO}

De acordo com Griensven et al, independentemente do esquema terapêutico utilizado, a co-infeção LV-VIH está associada a maior mortalidade e maior taxa de falência terapêutica e recaída. ${ }^{2}$ Lachaud et al (2009) demonstraram que o segundo episódio de LV no mesmo doente representa em $70 \%$ dos casos recaída, sendo identificado o mesmo perfil de estirpe. ${ }^{14}$ Noutras séries a percentagem de reinfecções é ainda menor $(7,5 \%) .{ }^{15}$ Para que seja feito o diagnóstico de recaída clínica de LV é necessária a confirmação biológica (em esfregaço ou exame cultural de sangue medular ou periférico) juntamente com pelo menos três critérios clínicos entre: febre intermitente, astenia, perda ponderal, sudorese, hepatomegalia, esplenomegalia, sintomas respiratórios ou gastrointestinais. Apesar de poderem existir as chamadas recaídas biológicas (recirculação transitória de parasitas detectados por técnica de PCR que é altamente sensível e que positiva com valores superiores a cinco parasitas $/ \mathrm{mL}$ ), as verdadeiras recaídas clínicas não ocorrem se a parasitémia for inferior a 10 parasitas $/ \mathrm{mL}$. Deste modo duas ou mais PCR sucessivas positivas, mesmo sem clínica, representam elevado risco preditivo de recaída ${ }^{8}$.

No estudo de Bourgeois et al, com uma amostra de 27 doentes co-infetados LV-VIH, foi identificada uma taxa de recaída de $59 \%,{ }^{8}$ um valor acima do identificado no presente estudo $(26,1 \%)$. De notar, no entanto, que o número de recaídas pode estar sub-avaliado, uma vez que nove doentes abandonaram o seguimento e os dois que recaíram mas que não tiveram seguimento poderão, na verdade, ter sido falências terapêuticas iniciais. Considerou-se a ausência de TARV $(p=0,036)$ e a contagem de células $\mathrm{TCD}_{4+}$ inferior a 100 células à data da primeira infeção $(p$ $=0,006$ ) como fatores preditivos de recaída, bem como a manutenção de valores de células $T C D_{4+}$ inferiores a 100 durante o período de seguimento $(p=0,005) .{ }^{8}$ Em contrapartida, a revisão sistemática de 18 artigos de Cota et al sobre fatores preditivos de recaída confirma a contagem de células $T C D_{4+}$ como o principal fator preditivo, não confirmando o cumprimento de TARV ou quaisquer outros fatores, nomeadamente a carga viral. ${ }^{16}$ Sabe-se que, quer o $\mathrm{VIH}$, quer a LV afectam a imunidade mediada por células $T$ e pensa-se que actuem sinergisticamente na redução da efetividade da resposta imune do hospedeiro. ${ }^{17}$ Assim, a baixa contagem inicial de células $T C D_{4+}$ permite a disseminação do parasita através do sistema mononuclear fago- cítico no início da infeção aumentando assim o número de locais que alojam parasitas quiescentes que se perpetuam (chamados 'santuários') ${ }^{16} \mathrm{e}$ onde a exposição aos fármacos é menor ${ }^{18}$ o que pode explicar as recaídas tão prevalentes neste subgrupo de doentes.

Já o cumprimento de profilaxia ou terapêutica de manutenção parece ser inequívoco na redução da taxa de recaída com taxas de $31 \%$ em doentes com profilaxia e $67 \%$ sem profilaxia. ${ }^{16}$ Estes dados são semelhantes ao apresentado no presente estudo, uma vez que dos 14 doentes que cumpriram quimioprofilaxia apenas quatro $(28,6 \%)$ recaíram. Os planos profiláticos propostos são variados, com vários regimes estudados nas estirpes mediterrânicas, sendo o mais consensual $3 \mathrm{mg} / \mathrm{kg}$ de anfotericina B lipossómica em administração endovenosa de 21 em 21 dias. ${ }^{7}$ Um estudo português de Marques et al demonstra, no entanto, que a utilização de miltefosine quer na terapêutica de recaída quer na terapêutica de manutenção (na dose de 50 mg, três vezes por semana) é eficaz, com um período livre de doença médio de 20 meses. ${ }^{19}$ É seguro descontinuar a profilaxia se a PCR de Leishmania no soro for negativa e a contagem de células $T C D_{4+}$ estiver controlada com TARV (> 200 cels/ $\mathrm{uL}$ ) pelo menos há mais de seis meses ou caso a contagem de células $\mathrm{TCD}_{4+}$ ainda seja inferior a 200 cels/uL mas a PCR seja negativa há mais de 18 meses. ${ }^{8}$ No entanto, tal como no presente estudo em que dois dos doentes que recaíram tinham, respectivamente, 281 e 362 células $\mathrm{TCD}_{4+} /$ uL, Villanueva et al identificaram dois casos de recaída com contagem de 274 e 302 células $\mathrm{TCD}_{4+} / \mathrm{uL},{ }^{20}$ pelo que se propôs a contagem de 350 células $\mathrm{TCD}_{4+}$ como limite para a suspensão da profilaxia. ${ }^{21}$ Apesar da profilaxia primária estar formalmente contra-indicada os IP poderão ser uma opção na TARV de doentes infetados ou com elevado risco de desenvolver LV, uma vez que podem actuar com efeitos antiparasitários diretos (as proteases do parasita podem ser um alvo inespecífico do IP). ${ }^{22}$

Falência terapêutica pode referir-se a falência inicial na eliminação do parasita no final do primeiro esquema terapêutico ou a uma recaída com reaparecimento do parasita no período de seguimento, habitualmente de seis meses, após cura inicial documentada. ${ }^{2}$ Todos os fármacos anti-Leishmania têm já descritos mecanismos de resistência, tendo sido recentemente descritos os mecanismos de resistência da anfotericina B [mutação do gene S-adenosil-L metionina C-24 esterol metiltransferase (SCMT) - enzima que actua na via de biossíntese do ergosterol constituinte da membrana, diminuindo a afinidade do fármaco pela célula e sobre-expressão do sistema de efluxo do fármaco, diminuindo a concentração do fármaco no interior da célula]. ${ }^{23}$ Face a esta situação, a literatura torna-se cada vez mais aliciante no que diz respeito à utilização de terapêutica combinada nestes doentes, uma vez que parece ser mais custo-efectiva, previne ou atrasa o aparecimento de resistências, preserva a sensibilidade e aumenta o tempo de vida útil do fármaco, reduz o tempo de tratamento e a dose total de cada fármaco, apresenta menor toxicidade e maior adesão terapêutica. ${ }^{2}$ 
No presente estudo, os casos de recaída tornaram-se desafios terapêuticos uma vez que após a primeira recaída todos recaíram ou tiveram falência terapeutica documentada num segundo episódio pelo menos uma vez (em média três vezes). Após vários ciclos terapêuticos em monoterapia (anfotericina B lipossómica, miltefosine), estes poderiam ser fortes candidatos a terapêutica combinada. Numa revisão de 2015 sobre LV, Makala et al descrevem seis estudos, a decorrer em fase II ou III, sobre terapêutica combinada da LV, mas todos em populações não co-infetadas. ${ }^{24}$ Também Sundar et al, adaptando as recomendações da OMS de 2010, confirmam a não-inferioridade dos esquemas combinados para tratamento de LV na Índia ( $L$. donovani) em áreas endémicas mas em doentes não co-infetados, sugerindo esquemas combinados de anfotericina $B$ lipossómica $5 \mathrm{mg} / \mathrm{kg}$ dose única com miltefosine sete dias, anfotericina $B$ lipossómica $5 \mathrm{mg} / \mathrm{kg}$ dose única com paromomicina 10 dias ou miltefosina com paromomicina 10 dias. ${ }^{25}$ No que diz respeito à população de co-infetados por LV-VIH no Mediterrâneo, em 2010, não havia ainda dados que suportassem qualquer esquema de terapêutica combinada. ${ }^{7}$ Um estudo indiano de 2015 com uma amostra de 102 doentes co-infetados por VIH testou a utilização de terapêutica combinada de anfotericina B lipossómica $30 \mathrm{mg} / \mathrm{kg}$ dividido em seis doses iguais administradas em dias alternados mais miltefosine $50 \mathrm{mg}$ duas vezes ao dia durante 14 dias. Quarenta e seis por cento dos doentes apresentavam a sua primeira infeção por Leishmania, mas $54 \%$ estariam em recaída tendo já realizado esquemas de monoterapia prévios. Dois doentes faleceram no decorrer do tratamento e 100 concluíram o esquema proposto, tendo-se observado uma taxa de recaída de $6 \%$ a 12 meses e uma mortalidade de $14,5 \%$. Apesar da mortalidade e recaídas serem sempre superiores nos doentes co-infetados comparativamente aos restantes, a terapia combinada apresenta uma taxa de recaída $(6 \%)$ menor que a conseguida com anfotericina $B$ em monoterapia $(16,2 \%) .{ }^{26}$

Hoje em dia as estratégias poupadoras de dose que encurtam o tempo de terapêutica parecem ser uma alternativa com grande potencial no tratamento da leishmaniose.

\section{REFERÊNCIAS}

1. Campino L, Maia C. Epidemiologia das leishmanioses em Portugal, Acta Med Port. 2010;23:859-64.

2. Van Griensven J, Balasegaram M, Meheus F, Alvar J, Lynen L, Boelaert M. Combination therapy for visceral leishmaniasis. Lancet Infect Dis. 2010;10:184-94.

3. Menezes J, Guedes C, Petersen A, Fraga D, Veras P. Advances in development of new treatment for leishmaniasis. Biomed Res Int. 2015;2015:815023.

4. Bern C. Clinical manifestations and diagnosis of visceral leishmaniasis. Up to date. [consultado $2016 \mathrm{fev}$ 16]. Disponivel em: https://www. uptodate.com/contents/search.

5. Alvar J, Velez ID, Bern C, Herrero M, Desjeux P, Cano J, et al. Leishmaniasis worldwide and global estimates of its incidence. PloS One. 2012;7:e35671.

6. Homepage/World Health Organization. who.int [homepage na Internet] Global Health Observatory data repository. Number of cases of visceral leishmaniasis reported. Data by country. [consultado 2016 mar 12]. Disponivel em http://www.who.int/en/.

7. Monge-Maillo B, Norman F, Cruz I, Açvar J, López-Vélez R.
Neste campo, a imunomodulação poderá vir a ter um papel importante, estimulando a resposta imunitária e atuando de forma sinérgica com a antibioterapia. Apenas confirmada na LV está a utilização do interferão em três estudos efetuados nos anos 90 em associação com anfotericina B, tendo-se abandonado o estudo nessa área. ${ }^{12}$

\section{CONCLUSÃO}

Este estudo vem reforçar a necessidade de considerar sempre o diagnóstico de LV nos doentes imunodeprimidos (principalmente em áreas endémicas como é o caso do nosso país e de toda a bacia mediterrânica). São doentes em que o processo de diagnóstico e principalmente de cura nem sempre é simples, mostrando-se ainda consideravelmente elevada a taxa de recaída associada à co-infeção LV-VIH com os vários esquemas de monoterapia disponíveis. A terapêutica combinada surge já na literatura como uma alternativa com múltiplas vantagens parecendo ser mais custo-efectiva e com menores taxas de recaída nesta população em particular.

\section{PROTECÇÃO DE PESSOAS E ANIMAIS}

Os autores declaram que os procedimentos seguidos estavam de acordo com os regulamentos estabelecidos pelos responsáveis da Comissão de Investigação Clínica e Ética e de acordo com a Declaração de Helsínquia da Associação Médica Mundial.

\section{CONFIDENCIALIDADE DOS DADOS}

Os autores declaram ter seguido os protocolos do seu centro de trabalho acerca da publicação de dados.

\section{CONFLITOS DE INTERESSE}

Os autores declaram não terem qualquer conflito de interesse relativamente ao presente artigo.

\section{FONTES DE FINANCIAMENTO}

Os autores declaram não ter recebido subsídios ou bolsas para a elaboração do artigo

Leishmaniasis and HIV coinfection in the Mediterranean region. PLoS Negl Trop Dis. 2014;8:e3021.

8. Bourgeois N, Lachau L, Reynes J, Rouanet I, Mahamat A, Bastien P. Long-term monitoring of visceral leishmaniasis in patients with AIDS Relapse risk factors, value of polymerase chain reaction and potential impact on secondary prophylaxis. J Acquir Immune Defic Syndr. 2008;48:13-9.

9. Russo R, Laguna F, López-Vélez R, Medrano FJ, Rosenthal E, Cacopardo B, et al. Visceral leishmaniasis in those infected with HIV: clinical aspects and other opportunistic infections. Ann Trop Med Parasitol. 2003;97:S99-105.

10. Pintado V, Martín-Rabadán P, Rivera ML, Moreno S, Bouza E. Visceral leishmaniasis in human immunodeficiency virus (HIV)-infected and nonHIV-infected patients. A comparative study. Medicine. 2001;80:54-73.

11. Cota GF, Sousa MR, Demarquin FN, Rabello A. The diagnostic accuracy of serologic and molecular methods for detecting visceral leishmaniasis n HIV infected patients: meta-analysis. PLoS Negl Trop Dis. 2012;6:e1665

12. Singh OP, Sundar S. Immunotherapy and targeted therapies in 
treatment of visceral leishmaniasis: current status and future prospects. Front Immunol. 2014;5:296.

13. Bern C. Treatment of visceral leishmaniasis. UpToDate. [consultado 2016 fev 16]. Disponível em: https://www.uptodate.com/contents/ search.

14. Lachaud L, Bourgeois N, Plourde M, Lephohon P, Bastien P, Ouellette M. Parasite susceptibility to amphotericin B in failures of treatment for visceral leishmaniasis $\mathrm{n}$ patients with HIV Type 1 and Leishmania infantum. Clin Infect Dis. 2009;48:e16-22

15. Morales MA, Cruz I, Rubio JM, Chicharro $C$, Cañavate $C$, Laguna $F$, et al. Relapses versus reinfections in patients coinfected with Leishmania infantum and human immunodeficiency virus type 1. J Infect Dis. 2002;185:1533-7.

16. Cota GF, Sousa MR, Rabello A. Predictors of visceral leishmaniasis relapse in HIV-infected patients: a sistematic review. PLoS Negl Trop Dis. 2011;5:e1153.

17. Patole S, Burza S, Varghese G. Multiple relapses of visceral leishmaniasis in a patient with HIV in India: a treatment challenge. Int J Infect Dis. 2014;25:204-6.

18. Achour N, Bouhamed R, Harrat Z. Profile of patients' visceral leishmaniasis-HIV co-infection in Kabylia. J AIDS Clin Res. 2017;8:649.

19. Marques N, Sá R, Coelho F, Oliveira J, Saraiva da Cunha S, MeliçoSilvestre A. Miltefosine for visceral leishmaniasis relapse treatment and secondary prophylaxis in HIV-infected patients. Scand J Infect Dis. 2008;40:523-6.
20. Villanueva JL, Alarcon A, Bernabeu-Wittel M, Cordero E, Prados D, Regordán C. Prospective evaluation and follow-up of European patients with visceral leishmaniasis and HIV-1 coinfection in the era of highly active antiretroviral therapy. Eur J Clin Microbiol. 2000;19:798-801.

21. Miró JM, Sanz J, Lozano F, Mallolas J, Moreno S, Aguirrebengoa K, et al. Prevention of opportunistic infections in HIV-infected adolescents and adults. Recommendations of GESIDA/National AIDS Plan. Enferm Infecc Microbiol Clin. 2008;26:437-64.

22. Van Griensven J, Diro E, Lopez-Velez R, Boalaert, Lynen L, Zijlstra E, et al A. HIV-1 protease inhibitors for treatment of visceral leishmaniasis in HIV-co-infected individuals. Lancet Infect Dis. 2013;13:251-9.

23. Purkait B, Kumar A, Nandi N, Sardar AH, Das S, Kumar S, et al Mechanism of amphotericin $B$ resistance in clinical isolates of leishmania donovani. Antimicrob Agents Chemother. 2012;56:1031-41.

24. Makala LH, Babak B. Novel therapeutic approaches to leishmania infection. [e-book] In: Claborn DM, editor. Leishmaniasis - trends in epidemiology, diagnosis and treatment. Chap. 21 p. 495-523 [consultado 2016 mar 23]. Disponível em: http://www.intechopen.com/ books/leishmaniasis-trends-in-epidemiology-diagnosis-and-treatment.

25. Sundar S, Chakravarty J. Recent advances in the diagnosis and treatment of kala-azar. Natl Med J India. 2012;25:85-9.

26. Mahajam R, Das $P$, Isaakidis $P$, Sunyo $T$, Sagili KD, Lima MA, et al. Combination treatment for visceral leishmaniasis patients coinfected with human immunodeficiency virus in India. Clin Infect Dis. 2015;61:125562 